\title{
Fault Identification and Islanding in DC Grid Connected PV System
}

\author{
M. Mano Raja Paul1', R. Mahalakshmi2, Murugesan Karuppasamypandiyan'3, \\ Ananthan Bhuvanesh', Rajendran Jai Ganesh ${ }^{5}$ \\ ${ }^{1}$ Department of EEE, Nehru Institute of Engineering \& Technology, Coimbatore, India \\ ${ }^{2}$ Department of EEE, Kumaraguru College of Technology, Coimbatore, India \\ ${ }^{3}$ Department of EEE, Kalasalingam University, Krishnankoil, India \\ ${ }^{4}$ Department of EEE, Mepco Schlenk Engineering College, Sivakasi, India \\ ${ }^{5}$ Department of EEE, K. Ramakrishnan College of Technology, Tiruchirapalli, India \\ Email: "manorajapaul06@gmail.com
}

Received 11 May 2016; accepted 23 May 2016; published 8 August 2016

Copyright (C) 2016 by authors and Scientific Research Publishing Inc.

This work is licensed under the Creative Commons Attribution International License (CC BY).

http://creativecommons.org/licenses/by/4.0/

(c) (i) Open Access

\begin{abstract}
Nowadays, the DC distribution system has been suggested, as a replacement for the AC power distribution system with electric propulsion. This idea signifies a fresh approach of issuing energy for low-voltage installations. It can be used for any electrical application up to $20 \mathrm{MW}$ and works at a nominal voltage of $1000 \mathrm{~V}$ DC. The DC distribution system is just an extension of the multiple DC links that previously available in all propulsion and thruster drives, which typically comprise more than $80 \%$ of the electrical power consumption on electric propulsion vessels. A fault detection and islanding scheme for DC grid connected PV system is presented in this paper. Unlike traditional ac distribution systems, protection has been challenging for dc systems. The goals of this paper are to classify and detect the fault in the PV system as well as DC grid and to isolate the faulted section so that the system keeps operating without disabling the entire system. The results show the measured values of power at PV panel and DC grid side under different fault condition, which indicates the type of fault that occurs in the system.
\end{abstract}

\section{Keywords}

PV System, DC Grid, Fault Identification, Islanding

\section{Introduction}

The escalating rates of fossil fuels forced the researchers to envisage the renewable energy system. The power

${ }^{*}$ Corresponding author.

How to cite this paper: Paul, M.M.R., Mahalakshmi, R., Karuppasamypandiyan, M., Bhuvanesh, A. and Ganesh, R.J. (2016) Fault Identification and Islanding in DC Grid Connected PV System. Circuits and Systems, 7, 2904-2915.

http://dx.doi.org/10.4236/cs.2016.710249 
generation from the fossil fuel may not be possible very long as they are depleting and also they are disadvantageous because they cause the environment pollution. Recently, the researchers are interested in the techniques for power generation with the renewable energy sources such as solar, hydro, wind, tidal biomass etc. The power generation using the renewable energy sources is advantageous because renewable energy sources are omnipresent, free of cost and maintenance and have longer life. Power generation based on PV sources has gradually increases during the last few decades [1]. This development has been matched with research into more efficient solar panels. Efficiency is calculated as the ratio of incident sun energy to the maximum attainable output power, with the recent record being an efficiency of $44.7 \%$ [2]. Along with research into solar panels, there is also an interest in the adjacent equipment. The efficiency of solar panels naturally ranges throughout the system, since any losses will disturb the final efficiency of the whole system. A DC grid system has been proposed as a power network that enables the introduction of a large amount of solar energy using distributed photovoltaic generation units. The standard configuration of a DC Grid Connected PV System (DCGCPV) is shown in Figure 1.

The energy produced by a DCGCPV system depends on various factors such as the nominal characteristics of the components of the PV system, electrical and geometrical configurations, weather conditions of site of installation mainly with respect to solar radiation availability, the local horizon and the near-field shading, availability of the plant, failures that may occur during its operation. A number of different issues can cause the loss of energy in the plant. Some losses are related to the PV array, these include maximum power point tracking error, module parameters dispersion (mismatch), wiring losses and ageing [3]. Others are influenced by environmental characteristics such as operating temperature, and solar irradiance level. In addition, others losses are referred to the power conditioning units (MPPT controller and DC-DC converters).

Currently, many identification techniques are established for possible faults detection in PV systems. Some of these do not need climate data such as the earth capacitance measurement (ECM) developed in [4], which having an electrical method for locating the disconnection of PV module in a string. The time-domain reflectometry (TDR) that measures the electrical characteristic of a transmission line, which can detect not only the disconnection in the string, but also the impedance change due to degradation is presented in [5]. A statistical method based on the ANOVA (Analysis of Variance) test and nonparametric Kruskale-Wallis test that displays a high level of accuracy and is fast in fault diagnosis is proposed in [6]. A remote monitoring and fault detection method of small GCPV systems is presented in [7], where climate data from satellites observation that replaces on-site measurements is used. Then, the expected energy yield is computed and compared with the measured one. The expected system's energy yields do not have the same accuracy than yields calculated from real measured data and values with root mean square error (RMSE) of about $10 \%$ have been stated for irradiance estimated using these methods [8]. Using this different types of faults can be identified: constant energy losses, variable energy losses [9] and losses due to the presence of snow. Other researchers used climate data measured by local sensors on the plants. A three layered feed forward neural network, to identify the short-circuit location of PV modules in one string is proposed in [10]. An intelligent system for automatic detection of faults in PV fields based on a Takagie Sugenoe Kahn Fuzzy Rule Based System (TSKFRBS) is described in [11]. The results show that the system can identify more than $90 \%$ of fault conditions, even when noisy data are introduced. Learning methods [12], for monitoring system simplifies the operation and maintenance of the PV systems, even if it needs many measurement sensors, which identify shading and inverter failure. A technique [13] that used only few measurement sensors, which can categorize the energy losses in four different types: sustained zero efficiency faults, brief zero efficiency faults, shading, and nonzero efficiency non-shading faults.

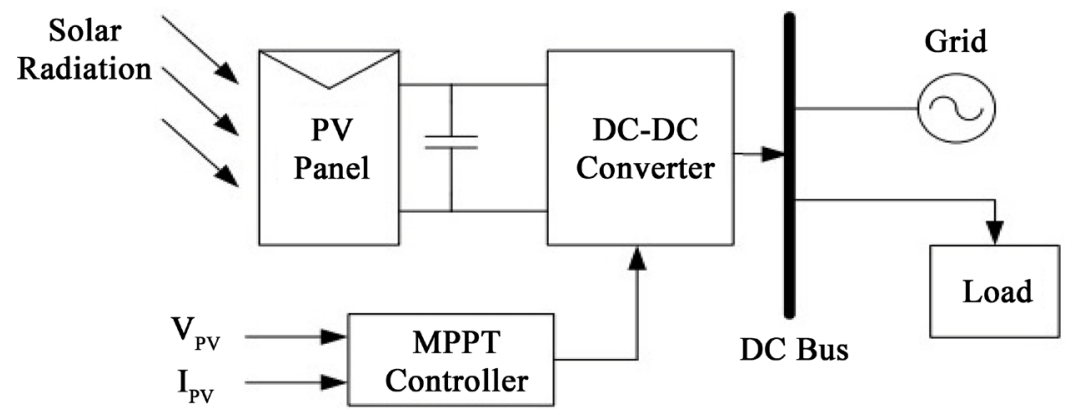

Figure 1. Standard configuration of a DCGCPV system. 
A simple investigative method to identify the number of open and short-circuited PV modules in a string with a small number of sensors is presented in [14]. Line to line fault that occurs under low irradiance conditions and occurring in PV arrays where blocking diode have been used is stated in [15]. A fault identification method based on the extended correlation function and the matter element model has been presented in [16]. The results show that the proposed fault diagnosis method detects the malfunction accurately and quickly. The $(-\mathrm{dI} / \mathrm{dV})-\mathrm{V}$ characteristic to detect the partial shadow phenomenon is proposed in [17]. The fault detection and classification method based on decision trees (DT) is presented in [18].

A fault detection algorithm acting on the power conditioning system of the PV plant using wavelet transform is proposed in [19]. This method detects the fault and its location without any additional hardware. But this method has high cost and re-design problem if the inverter specification has been changed. An automatic fault detection method based on the power losses analysis is proposed in [20]. This method detects faults that occur only on the DC side of the PV system. The method can identify four different types of faults: faulty modules in a string, faulty string, false alarm and combined faults such as partial shadow, ageing, and MPPT error. In this paper, the classification, detection and islanding of all possible faults in DCGCPV system are presented, where $250 \mathrm{~W}, 12 \mathrm{~V}$ array connected to a $500 \mathrm{~W}, 58 \mathrm{~V}$ grid via a DC-DC boost converter.

\section{Classification of Faults in DCGCPV System}

Faults in DCGCPV system can be classified into two types: PV side and DC grid side. The all possible faults may occur in DCGCPV system is shown in Figure 2.

\subsection{Faults in PV System}

The faults occur in the PV system are classified into three major types: fault in PV array, fault in MPPT and fault in DC-DC converter.

\subsubsection{Faults in PV Array}

Faults in PV arrays involve two main groups, PV panel fault and cabling. The most common types of fault in PV Panel/Module are Earth Fault, Bridge Fault, Open Circuit Fault and Mismatch Fault.

\section{a) PV panel/Module Faults \\ 1) Earth Fault}

Earth fault occurs when the circuit develops an unintentional path to ground. Two types of grounding shall be provided for PV system such as system grounding and equipment grounding. In system grounding, the negative conductor is grounded through the Earth fault protection device. The exposed non-current-carrying metal parts of PV module frames, electrical equipment, and conductor enclosures should be grounded in equipment grounding. Two types of Earth faults namely Lower Earth fault and Upper Earth fault can occur. In Lower Earth fault,

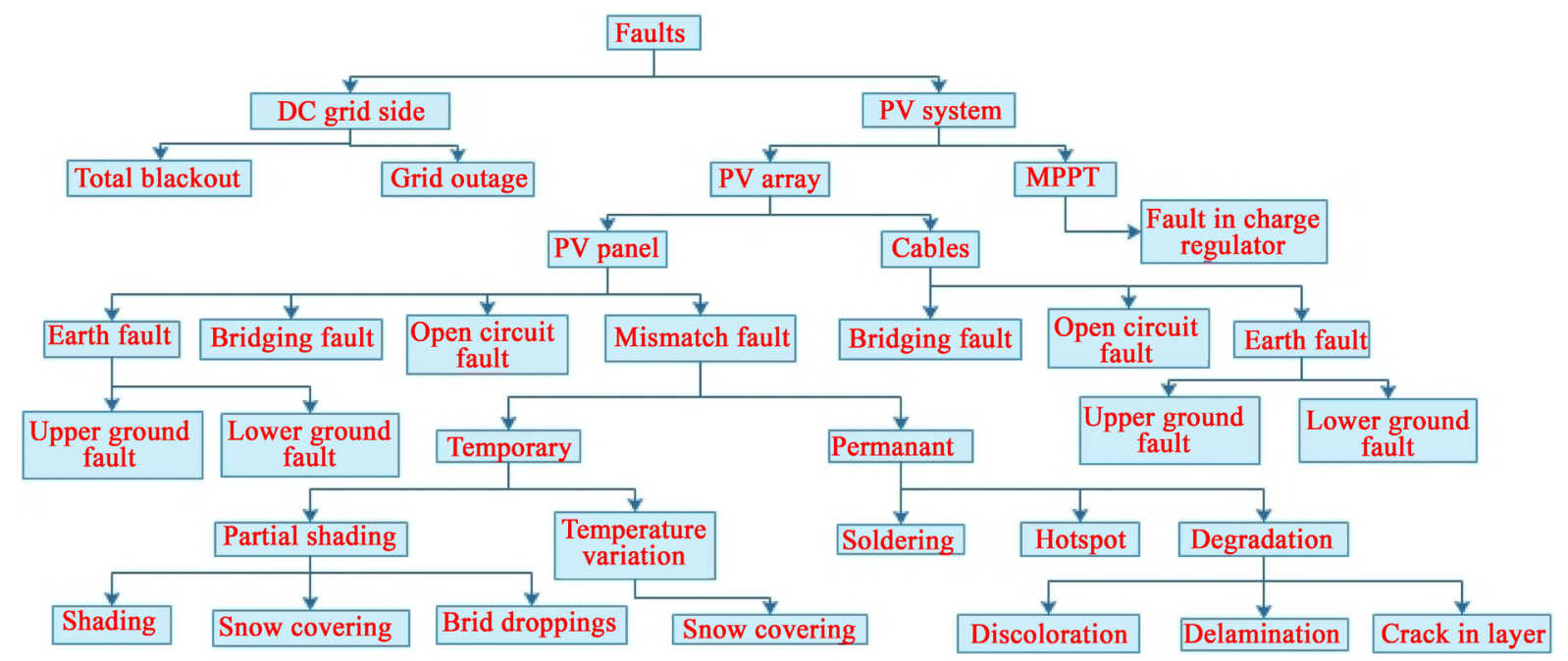

Figure 2. Classification of faults in DCGCPV system. 
the potential fault point is upper than half of the maximum voltage power point. And the Upper Earth fault will create large backed current and very high Earth-fault current. Without any sensor, these faults are identified, when the sign of the monitored primary grid current is changed [21].

\section{2) Bridging fault}

When low-resistance connection recognized between two points of different potential in string of module or cabling, the bridging fault will occur. Insulation failure of cables such as an animal chewing through cable insulation, mechanical damage, water ingress or corrosion cause these faults.

\section{3) Open Circuit Fault}

An open circuit fault occurs, when one of the current-carrying paths in series with the load is broken or opened. The poor connections between cells, plugging and unplugging connectors at junction boxes, or breaks in wires cause these fault.

\section{4) Mismatch Fault}

When the electrical parameters of one or group of cell are changed from other, the mismatches in PV modules will occur. These fault results in irreversible damage on PV modules and large power loss. These faults can be classified into permanent and temporary mismatches.

Temporary mismatches occur when a part of the panels array are shaded by shade from the building itself, light posts, chimneys, trees, clouds, dirt, snow and other light-blocking obstacles [22]. Non-uniform temperature can be identified due to snow covering.

Permanent mismatch occurs due to faults in hotspot, soldering and degradation. Hot spot heating happens when the operating current exceeds the reduced short circuit current of a shadowed or faulty cell or group of cells within the module [23].

Soldering fault can be identified in resistive solder bond between cell and contacted ribbons. Discoloration, delamination and transparent layer crack result in degradation fault.

\section{b) Fault in cables}

Bridging Fault, Open-Circuit fault and Earth Fault are occurring in power line carrier and cabling system. An aged connection box at the back side of a solar panel or in the corner and bend aria of cable cause bridging fault [24]. Upper earth and lower earth faults occur between panels and ground. It results in dropped output voltage and power, and can be dangerous if the leakage currents are running through a person.

\subsubsection{MPPT Fault}

MPPT increases the power fed to the grid from PV array. The performance of MPPT degrades when the failure occurs in the charge regulators. The output voltage and the output power reduces when fault occur in MPPT.

\subsubsection{DC-DC Converter Fault}

DC-DC converters change DC power from one voltage level to another. The power semiconductor switches are the most breakable components due factors like environmental varying conditions, system transient, heavy load, thermal/power cycles, manufacturing defects etc [25]. List of fragile components according to failure rates in DC-DC converters by the survey report in descending order is power switching devices, capacitors, gate driver circuits, connectors, inductors, resistors and other devices. It is reported that $66 \%$ failures occur in power processing stages of PV systems [26], the life span of the power processing stages is very short as compared to the life span of solar PV array.

\subsection{Faults in DC Grid Side}

In DC grid side two types of faults can be identified: total black out which measured as exterior fault for system, lighting and unbalanced voltage or grid outage for DC part defect such as weaker switch, over current or over voltage and etc.

\section{Modelling of DCGCPV System}

The schematic diagram of the PV system is shown in Figure 3. It consists of PV panel, boost converter and MPPT controller. The PV panel is the series and parallel combination of the PV modules. A high valued capacitor $\mathrm{C}_{\mathrm{B}}$ is connected across the PV panel terminal to reduce the harmonics, which is generated due to variation in temperature and solar irradiation. 


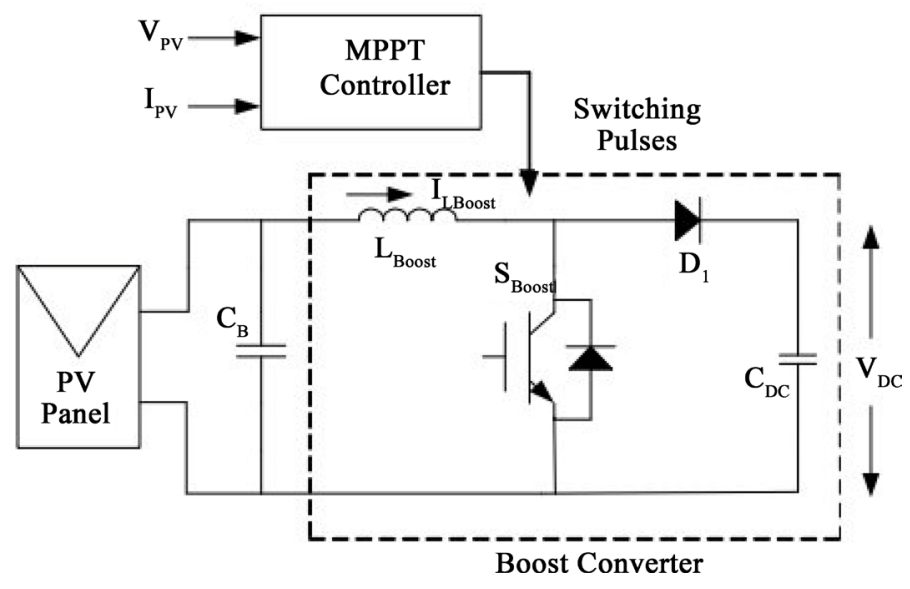

Figure 3. Schematic diagram of the PV system.

The Mathematical modelling of the PV array can be given as

$$
I=N_{p} I_{p h}-N_{p} I_{D}\left[\exp \left(\frac{q}{k T A} \times \frac{V_{p v}}{N_{s}}\right)-1\right]
$$

The diode reverse saturation current $I_{D}$ varies with the temperature according to the following equation,

$$
I_{D}=I_{r r}\left[\frac{T}{T_{r}}\right]^{3} \exp \left(\frac{q E_{G}}{k A}\left[\frac{1}{T_{r}}-\frac{1}{T}\right]\right)
$$

The energy gap of the semiconductor used in the PV cell dependent on the temperature is given as:

$$
E_{G}=E_{G}(0)-\frac{\propto T^{2}}{T+\beta}
$$

The photo current $I_{p h}$ depends on the solar radiation and cell temperature as follows

$$
I_{p h}=\left[I_{s c r}+K_{i}\left(T-T_{r}\right)\right] \frac{S}{100}
$$

The PV power can be calculated using the following expression,

$$
P=I V=N_{p} I_{p h}\left[\left(\frac{q}{k A T} \times \frac{V}{N_{s}}\right)-1\right]
$$

The effects of solar irradiation and temperature have been considered while designing the PV panel. The variation in solar irradiation causes changes in output power and the temperature affects the terminal voltage. The generated DC voltage of the PV panel is very low for the application. Hence, the generated DC voltage level is increased using the DC-DC boost converter. The boost converter simply controls the output voltage of the PV panel $\left(V_{P V}\right)$ to a constant dc link voltage $\left(V_{D C}\right)$. The converter also performs the MPPT function for acquiring high energy conversion efficiency. The MPPT controller uses the Incremental conductance with Integral Regulator MPPT technique by considering the PV panel voltage and current. The modeling of the DC-DC converter depends on the various sequences of operation by controlling the duty ratio $D$. There are two sequence of operation of converter depending on the state of the IGBT switch $\left(\mathrm{S}_{\mathrm{B}}\right)$.

When the switch is in ON state,

$$
\begin{gathered}
V_{p v}=L_{B} \frac{\mathrm{d} I_{p v}}{\mathrm{~d} t} \\
0=C_{D C} \frac{\mathrm{d} V_{D C}}{\mathrm{~d} t}+I_{D C}
\end{gathered}
$$


When the Switch is in OFF State,

$$
I_{p v}=C_{D C} \frac{\mathrm{d} V_{D C}}{\mathrm{~d} t}+I_{D C}
$$

By considering that $D=1$, when switch is in ON state and $D=0$, when switch is in OF state, the converter can be represented by the single system of equation,

$$
\begin{gathered}
V_{p v}=L_{B} \frac{\mathrm{d} I_{p v}}{\mathrm{~d} t}+V_{D C}(1-D) \\
(1-D) I_{p v}=C_{D C} \frac{\mathrm{d} V_{D C}}{\mathrm{~d} t}+I_{D C}
\end{gathered}
$$

From Equation (9) and Equation (10)

$$
\begin{aligned}
& \frac{\mathrm{d} I_{p v}}{\mathrm{~d} t}=-(1-D) \frac{V_{D C}}{L_{B}}+\frac{V_{p v}}{L_{B}} \\
& \frac{\mathrm{d} V_{D C}}{\mathrm{~d} t}=(1-D) \frac{I_{p v}}{C_{D C}}-\frac{I_{D C}}{C_{D C}}
\end{aligned}
$$

The PV array can be controlled for obtaining the maximum power point by the regular correction in duty ratio (D), which is obtained by the MPPT controller. The MPPT controller also controls the $D$, for maintaining the regular voltage using the reference voltage and generates the control signal for the converter switch $\mathrm{S}_{\mathrm{B}}$.

The deviations occur in PV power can be calculated by the above equations, when the DCGCPV system operates under faulty condition.

The DCGCPV system is designed with the specification, which is given in Table 1.

\section{Result and Discussion}

The fault identification and islanding scheme on DCGCPV system has been done using MatLab Simulink model and hardware.

\subsection{Simulation Results}

The simulation for fault identification have been done under five different conditions such as no fault, fault in PV panel, MPPT fault, DC-DC converter fault and grid fault. The developed MatLab Simulink model of DCGCPV system to identify faults is shown in Figure 4. The Simulink model having two areas such as PV side and DC grid side. The power produced by PV panel is applied to the grid through the breaker device. The breaker will open automatically and stop the power flow when fault occurs in PV panel.

\subsubsection{No Fault Condition}

The output power available at PV system and grid under normal operating condition are shown in Figure 5.

Figure 5 shows that the output power will increase gradually, when the PV panel start to feed the power into the grid. The PV panel inject the maximum power of $248 \mathrm{~W}$ into the grid. The maximum of $1040 \mathrm{~W}$ of power can be extracted at grid, when the DCGCPV system is operating under normal condition.

\subsubsection{Fault in PV Panel}

The power fed into the grid will degraded when the fault occurs in the PV panel. The output power available at

\section{Table 1. Specification of DCGCPV system.}

\begin{tabular}{cc}
\hline Components & Specification \\
\hline PV array & $250 \mathrm{~W}$ capacity, $12 \mathrm{~V}$ voltage, $0.62 \Omega$ series resistance, $250.57 \Omega$ shunt resistance, $5.12 \mathrm{~A}$ short circuit current \\
MPPT & Incremental Conductance + Integral Regulator technique \\
DC-DC Converter & Converts $12 \mathrm{~V}$ DC to $58 \mathrm{~V}$ DC \\
Grid alone & $500 \mathrm{~W}$ capacity, $58 \mathrm{~V}$ voltage \\
\hline
\end{tabular}




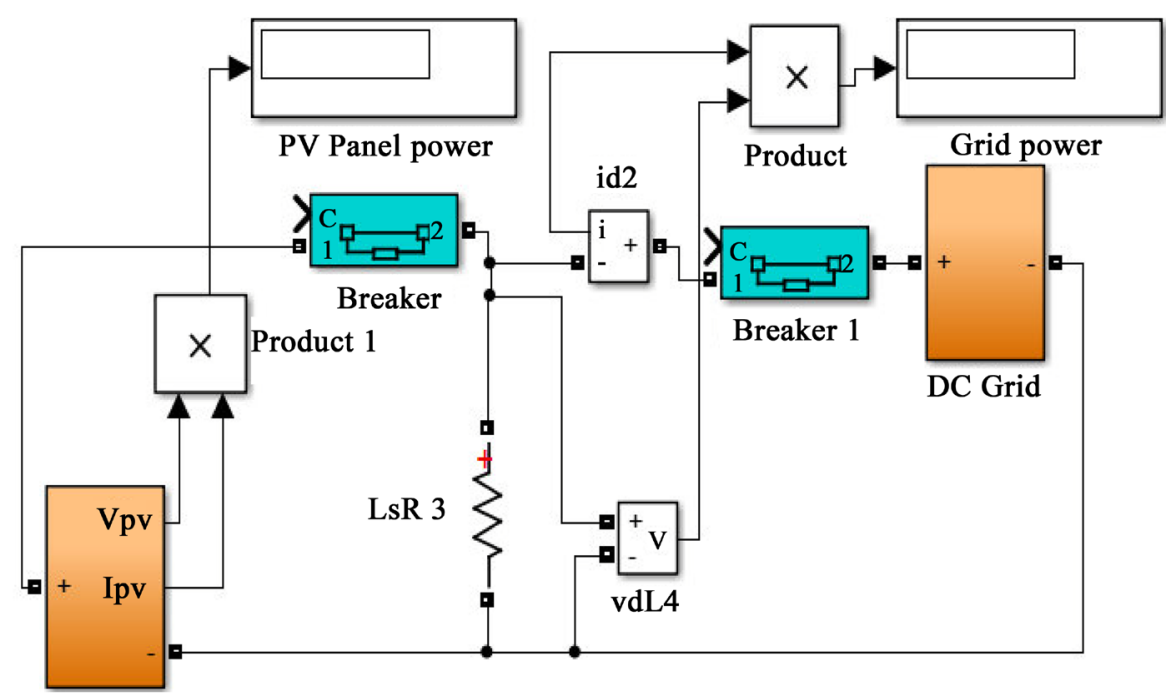

PV Panel with MPPT

Figure 4. The developed MatLab Simulink model of DCGCPV system.

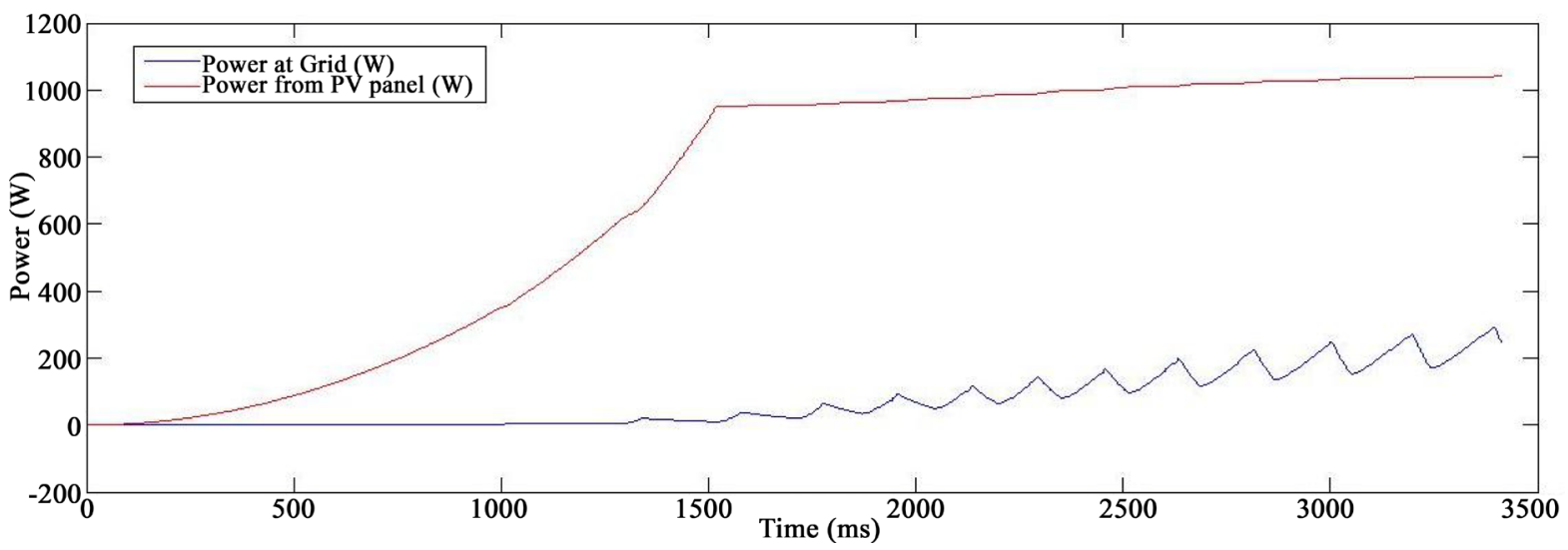

Figure 5. PV panel and grid power under no fault condition.

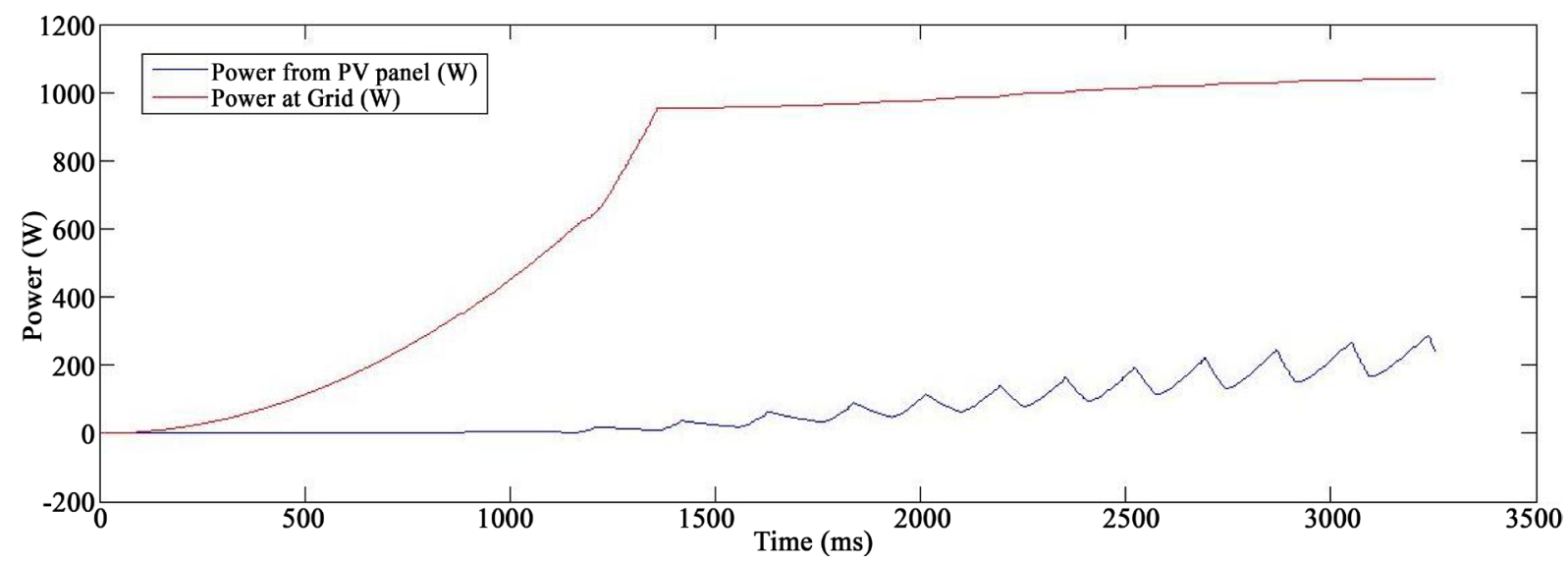

Figure 6. PV panel and grid power under PV panel fault condition.

PV system and grid under PV panel fault condition are shown in Figure 6.

The power injection into the grid by the PV panel is reduced to $200 \mathrm{~W}$, when the fault occurs in PV panel. So the power extracted at grid is also reduced to $1000 \mathrm{~W}$. 


\subsubsection{Fault in MPPT}

The PV panel will lose its maximum power tracking ability when the fault occurs in MPPT. So the output power from the PV panel is degraded. The output power available at PV system and grid under MPPT fault condition are shown in Figure 7.

Figure 7 shows that the maximum power extracted by the PV panel will reduced below $70 \mathrm{~W}$, when the MPPT fails to operate normally. So the power injected into the grid is also reduced.

\subsubsection{Fault in DC-DC Converter}

When the DC-DC converter fails to operate normally, the voltage boosting will not happen. When the voltage can be boosted up, the power extraction becomes low. The output power available at PV system and grid under DC-DC converter fault condition are shown in Figure 8.

The voltage as well as the power can't be boosted up over a certain level, when the fault occurs in DC-DC converter. In this case, the generated power from the PV panel can't be boosted up more than $100 \mathrm{~W}$.

\subsubsection{Fault in DC Grid}

The PV panel works normally but the DC grid cannot provide the rated output power, when the faults occur in DC grid. The output power available at PV system and grid under DC grid fault condition are shown in Figure 9.

Figure 9 shows that the PV panel injects rated power of $240 \mathrm{~W}$ into the grid. But the grid power reduced to $600 \mathrm{~W}$. Under this condition the islanding must be performed. Islanding is the situation in which a distribution system becomes electrically isolated from the rest of the power system, yet continues to be energized by DG connected to it. An overview of islanding detection methods in PV systems have been presented in [27].

Injected Current Perturbation (ICP) technique [28] is carried out on DCGCPV system to isolate the PV system from the DC grid. The output power available at PV system and grid after islanding are shown in Figure 10.

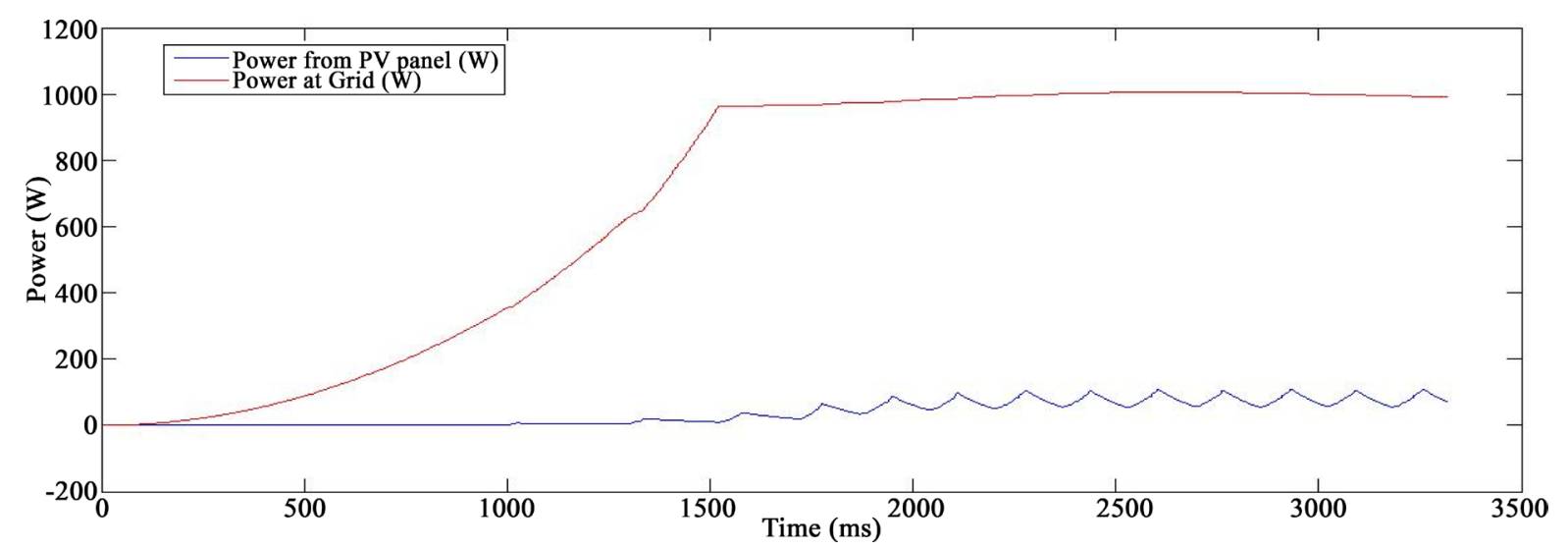

Figure 7. PV panel and grid power under MPPT fault condition.

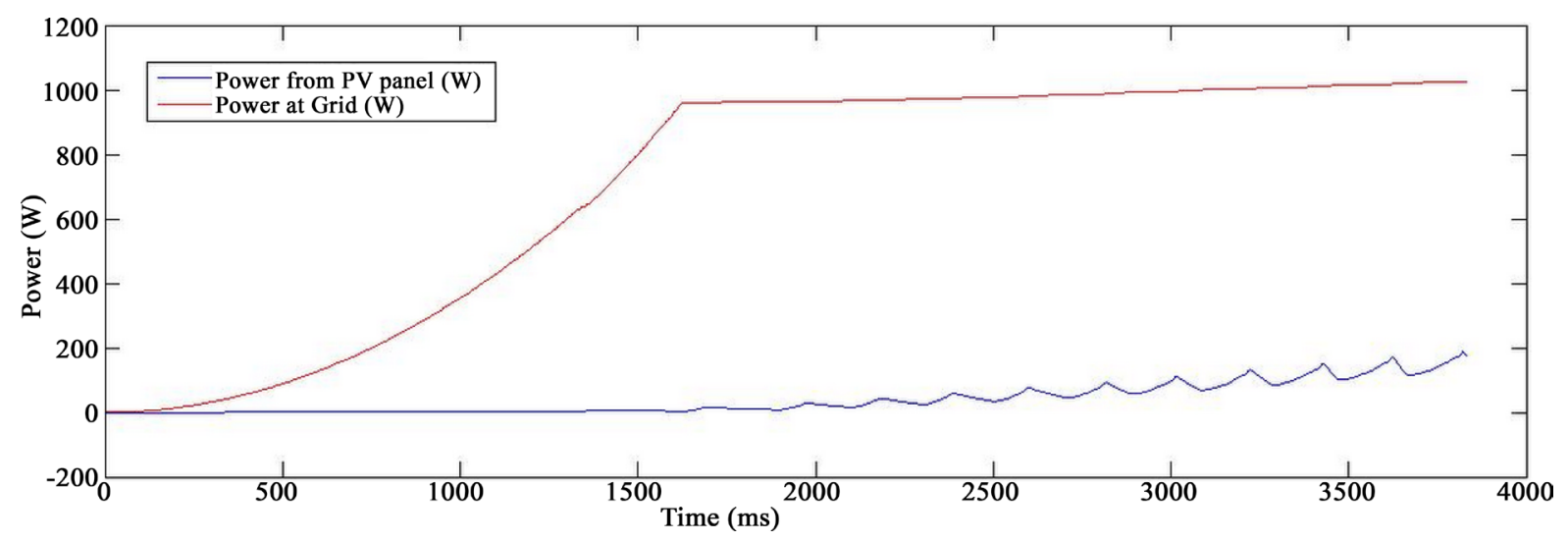

Figure 8. PV panel and grid power under DC-DC converter fault condition. 


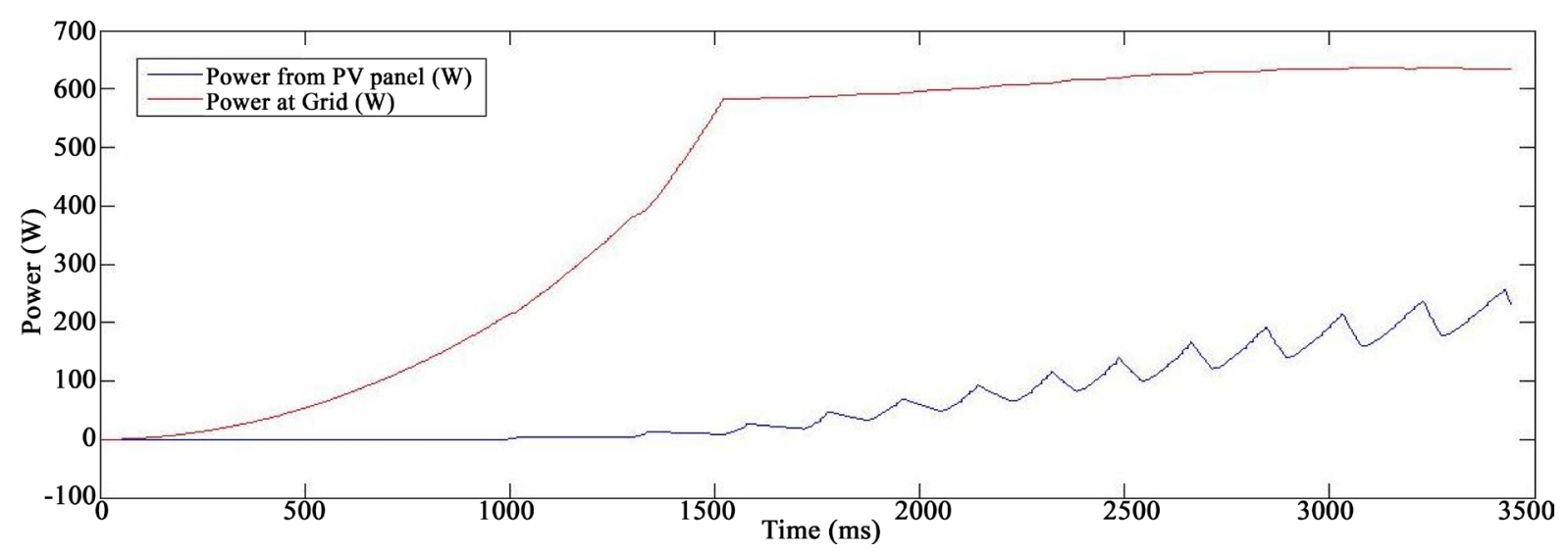

Figure 9. PV panel and grid power under DC grid fault condition.

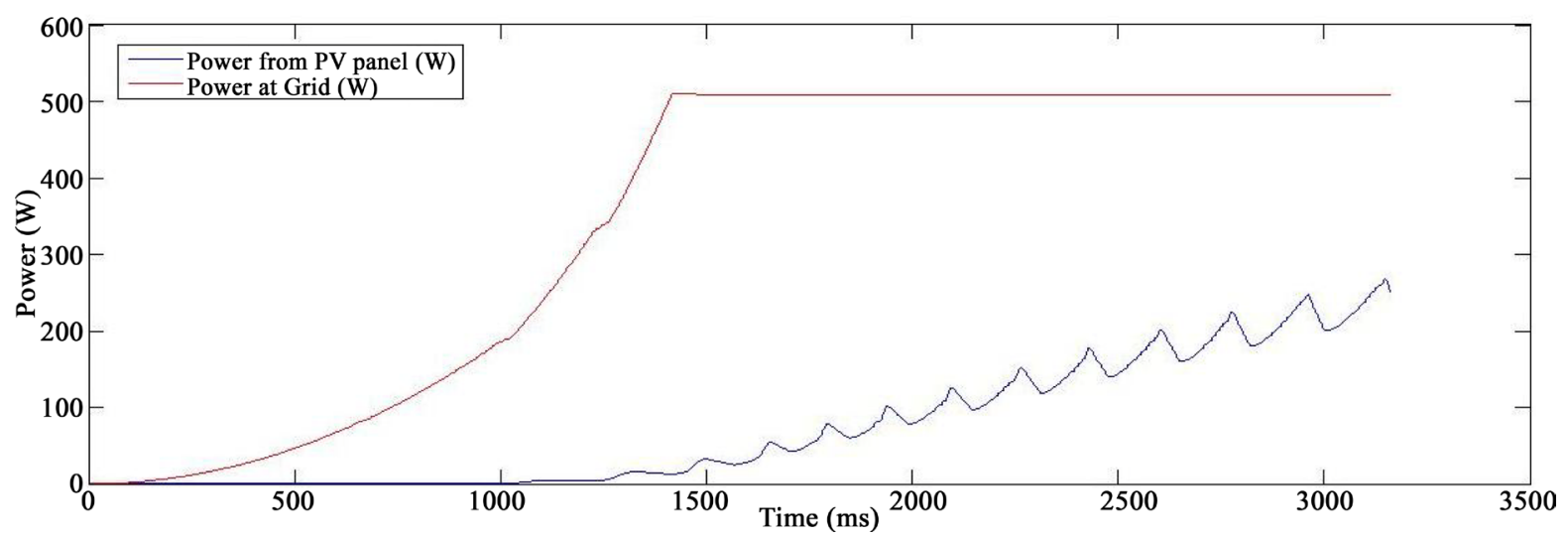

Figure 10. PV panel and grid power after islanding.

When islanding is performed, there will be no power injection into the grid by the PV panel. Figure 10 shows that the PV power of $248 \mathrm{~W}$ and grid power of $500 \mathrm{~W}$ under isolated condition.

\subsection{Experimental Results}

The DCGCPV system has been designed using the specification given in Table 2. Figure 11 shows the experimental setup of DCGCPV system for fault identification and islanding.

The faults are manually created on the DCGCPV system and the current and voltage values are measured. The measured values of current and voltage at PV panel and Grid side, under different fault conditions are tabulated in Table 2.

Figure 12 shows the comparison of the measured power in experimental results of PV panel and DC grid. Under no fault condition the current and voltage are in rated values, so the PV panel inject its maximum power of $250 \mathrm{~W}$ into the grid. During PV panel fault and MPPT fault, the current flow from the PV panel becomes low, so the power generated from the PV panel is also low, which result in reduced power injection into the grid at the rate of $200 \mathrm{~W}$. When the manual fault is created in DC-DC converter, it loose its ability to boost the voltage. This results in low power injection into the grid. The PV panel injects its maximum power into the grid, but the power extracted at the grid is low. This event happens only during grid failure. So the islanding techniques are performed to isolate the PV panel from the grid.

\section{Conclusions}

The classification and detection methods of the fault in the PV system as well as DC grid are presented in this paper. Moreover, the islanding method has been performed during the grid fault to isolate the PV system, without disabling the entire system. This procedure has been tested using monitored data of a $250 \mathrm{~W}, 12 \mathrm{~V}$ array 
Table 2. Measured values of current and voltage at PV panel and grid side, under different fault conditions.

\begin{tabular}{ccccccc}
\hline \multirow{2}{*}{ Type of fault } & \multicolumn{3}{c}{ PV panel } & \multicolumn{3}{c}{ DC Grid } \\
\cline { 2 - 7 } & Current (A) & Voltage(V) & Power (W) & Current (A) & Voltage(V) & Power (W) \\
\hline No fault & 4.17 & 57.43 & 240 & 17.93 & 58 & 1040 \\
PV panel fault & 3.99 & 50.21 & 200 & 17.34 & 57.65 & 1000 \\
MPPT fault & 1.72 & 40.57 & 70 & 17.06 & 56.24 & 960 \\
DC-DC converter fault & 4.16 & 24.01 & 100 & 17.18 & 57.04 & 980 \\
DC grid fault & 4.28 & 57.12 & 245 & 15.96 & 38.21 & 610 \\
\hline
\end{tabular}

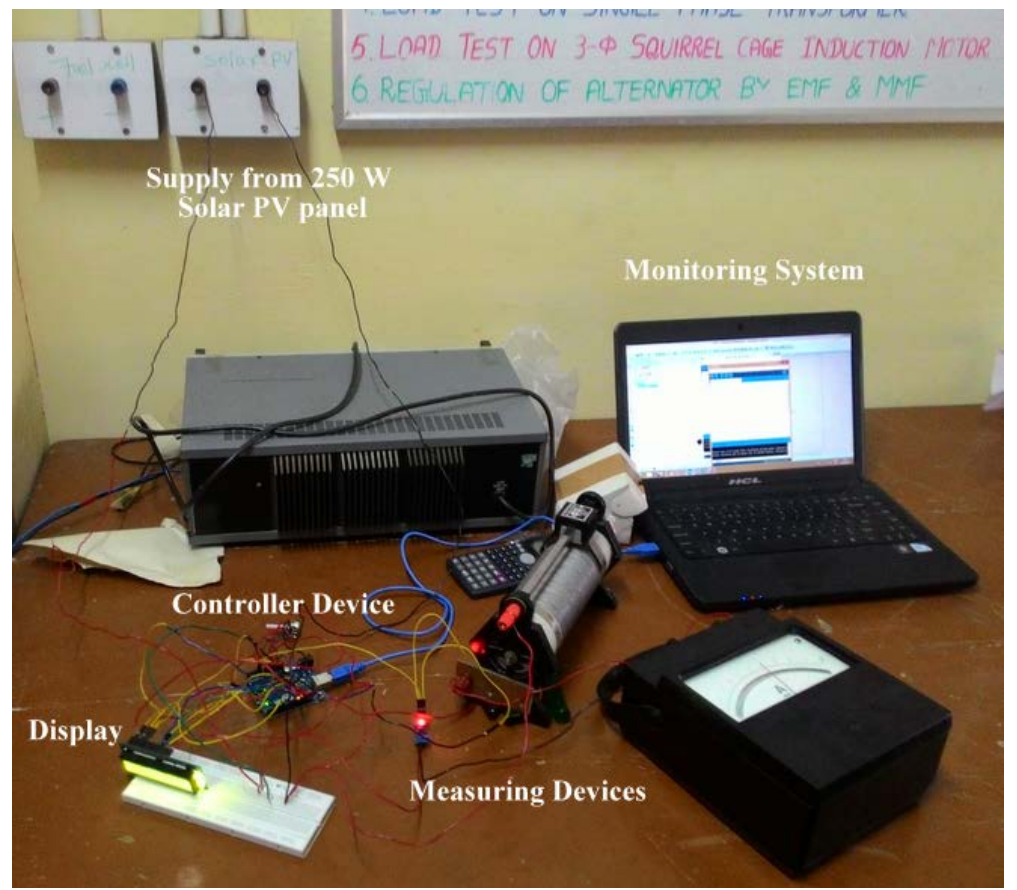

Figure 11. Experimental setup of DCGCPV system for fault identification and islanding.

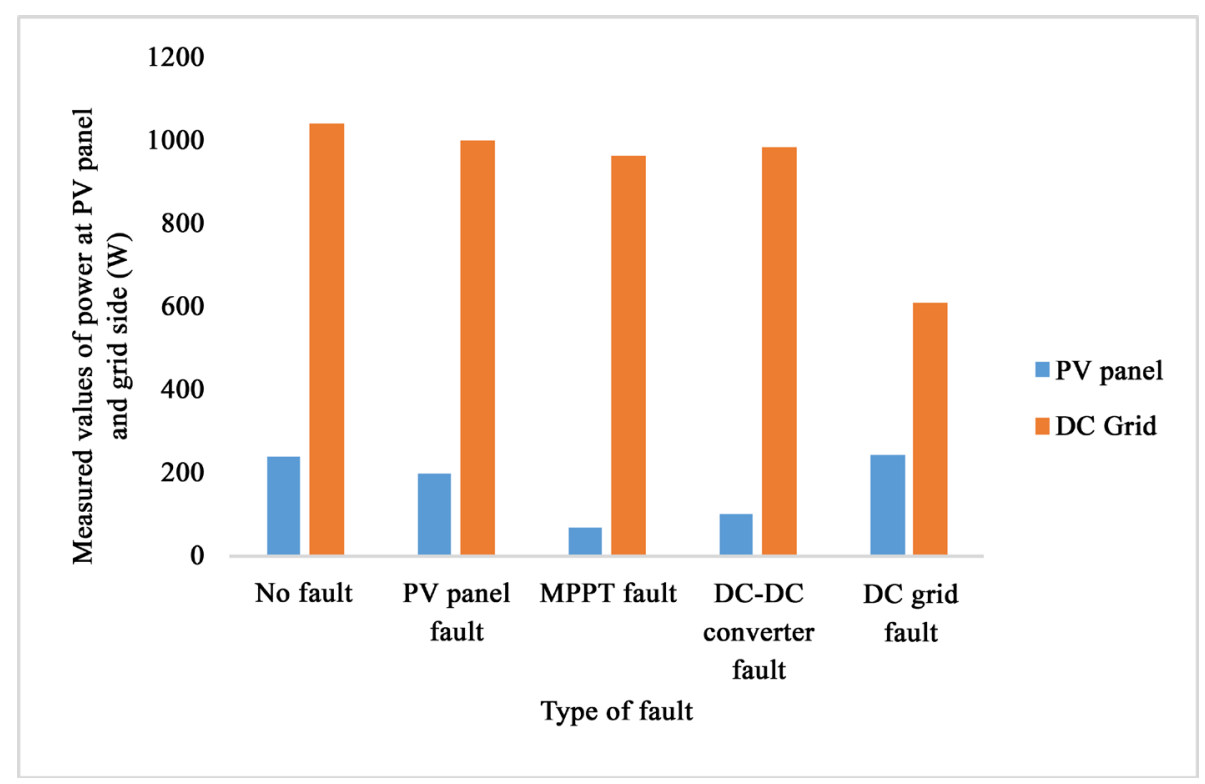

Figure 12. Comparison of the measured power in PV panel and DC grid. 
connected to a $500 \mathrm{~W}, 58 \mathrm{~V}$ grid via a DC-DC boost converter. Five case studies have been presented: no fault, fault in PV panel, MPPT fault, DC-DC converter fault and grid fault. Results confirm the feasibility of fault diagnosis method of DCGCPV plants with good accuracy.

In the future, we aim to implement an automatic diagnosis procedure experimentally into low cost microcontroller, with LCD display and flash alarm to notify users about the state of their systems in real time.

\section{Acknowledgements}

The authors gratefully acknowledge the managements of Nehru Institute of Engineering \& Technology, Kumaraguru College of Technology, Coimbatore, Kalasalingam University, Mepco Schlenk Engineering College, Viruthunagar for their constant support and encouragement during this research.

\section{References}

[1] Zhao, Y. (2010) Fault Analysis in Solar Photovoltaic Arrays. Master's Thesis, Northeastern University.

[2] World Record Solar Cell with 44.7\% Efficiency. http://phys.org/news/2013-09-world-solar-cell-efficiency.html

[3] Nordmann, T., Jahn, U. and Nasse, W. (2004) Performance of PV Systems under Real Conditions. Proceedings of the European Workshop on Life Cycle Analysis and Recycling of Solar Modules, the Waste Challenge, Brussels.

[4] Takashima, T., Yamaguchi, J., Otani, K., Oozeki, T., Kato, K. and Ishida, M. (2009) Experimental Studies of Fault Location in PV Module Strings. Solar Energy Materials and Solar Cells, 93, 1079-1082. http://dx.doi.org/10.1016/j.solmat.2008.11.060

[5] Schirone, L., Schirone, L., Califano, F.P. and Pastena, M. (1994) Fault Detection in a Photovoltaic Plant by Time Domain Reflectometry. Progress in Photovoltaics: Research and Applications, 2, 35-44. http://dx.doi.org/10.1002/pip.4670020106

[6] Vergura, S., Acciani, G., Amoruso, V. and Patrono, G. (2008) Inferential Statistics for Monitoring and Fault Forecasting of PV Plants. Proceedings of the IEEE International Symposium, Industrial Electronics, Cambridge, 2414-2419.

[7] Drews, A., de Keizer, A.C., Beyer, H.G., Lorenz, E., Betcke, J. and van Sark, W.G.J.H.M. (2007) Monitoring and Remote Failure Detection of Grid-Connected PV Systems Based on Satellite Observations. Solar Energy, 81, 548-564. http://dx.doi.org/10.1016/j.solener.2006.06.019

[8] Muselli, M., Notton, G., Canaletti, J.L. and Louche, A. (1998) Utilization of Meteosat Satellite Derived Radiation Data for Integration of Autonomous Photovoltaic Solar Energy Systems in Remote Areas. Energy Conversion and Management, 39, 1-19. http://dx.doi.org/10.1016/S0196-8904(96)00183-5

[9] Drif, M., Mellit, A., Aguilera, J. and Perez, P.J. (2012) A Comprehensive Method for Estimating Energy Losses Due to Shading of GC-BIPV Systems Using Monitoring Data. Solar Energy, 86, 2397-2404. http://dx.doi.org/10.1016/j.solener.2012.05.008

[10] Syafaruddin, S., Karatepe, E. and Hiyama, T. (2011) Controlling of Artificial Neural Network for Fault Diagnosis of Photovoltaic Array. Proceedings of the 16th International Conference on Intelligent System Application to Power Systems (ISAP), Greece, 1-6.

[11] Ducange, P., Fazzolari, M., Lazzerini, B. and Marcelloni, F. (2011) An Intelligent System for Detecting Faults in Photovoltaic Fields. Proceedings of the IEEE 11th International Conference on Intelligent Systems Design and Applications, Cordoba, 1341-1346.

[12] Yagi, Y., Kishi, H., Hagihara, R., Tanaka, T., Kozuma, S. and Ishida, T. (2003) Diagnostic Technology and an Expert System for Photovoltaic Systems Using the Learning Method. Solar Energy Materials and Solar Cells, 75, 655-663. http://dx.doi.org/10.1016/S0927-0248(02)00149-6

[13] Firth, S.K., Lomas, K.J. and Rees, S.J. (2010) A Simple Model of PV System Performance and Its Use in Fault Detection. Solar Energy, 84, 624-635. http://dx.doi.org/10.1016/j.solener.2009.08.004

[14] Gokmen, N., Karatepe, E., Celik, B. and Silvestre, S. (2012) Simple Diagnostic Approach for Determining of Faulted PV Modules in String Based PV Arrays. Solar Energy, 86, 3364-3377. http://dx.doi.org/10.1016/j.solener.2012.09.007

[15] Zhao, Y., Lehman, B., De Palma, J.F., Mosesian, J. and Lyons, R. (2011) Challenges to Overcurrent Protection Devices under Line-Line Faults in Solar Photovoltaic Arrays. Proceedings of the IEEE Energy Conversion Congress and Exposition (ECCE), Phoenix, 20-27.

[16] Chao, K.H., Ho, S.H. and Wang, M.H. (2008) Modelling and Fault Diagnosis of a Photovoltaic System. Electrical Power System Research, 78, 97-105. http://dx.doi.org/10.1016/j.epsr.2006.12.012

[17] Miwa, M., Yamanaka, S., Kawamura, H., Ohno, H. and Kawamura, H. (2006) Diagnosis of a Power Output Lowering of PV Array with a (-dI/dV)-V Characteristic. Proceeding of IEEE 4th World Conference on Photovoltaic Energy 
Conversion, 2, 2442-2445. http://dx.doi.org/10.1109/wcpec.2006.279703

[18] Zhao, Y., Yang, L., Lehman, B., DePalma, J.F., Mosesian, J. and Lyons, R. (2012) Decision-Based Fault Detection and Classification in Solar Photovoltaic Arrays. Proceedings of the 27th Annual IEEE Applied Power Electronics Conference and Exposition, Orlando, 5-9 February 2012, 93-99. http://dx.doi.org/10.1109/apec.2012.6165803

[19] Il-Song, K. (2010) Fault Detection Algorithm of the Photovoltaic System Using Wavelet Transform. India International Conference on Power Electronics 2010 (IICPE2010), New Delhi, 28-30 January 2011, 1-6.

[20] Chouder, A. and Silvestre, S. (2010) Automatic Supervision and Fault Detection of PV Systems Based on Power Losses Analysis. Energy Conversion and Management, 51, 1929-1937. http://dx.doi.org/10.1016/j.enconman.2010.02.025

[21] Strobl, C. and Meckler, P. (2010) Arc Faults in Photovoltaic Systems. Proceedings of the 56th IEEE Holm Conference on Electrical Contacts, Charleston, 4-7 October 2010, 1-7. http://dx.doi.org/10.1109/holm.2010.5619538

[22] Ancuta, F. and Cepisca, C. (2011) Fault Analysis Possibilities for PV Panels. Proceedings of the 2011 3rd International Youth Conference on Energetics (IYCE), Leiria, 7-9 July 2011, 1-5.

[23] Wendlandt, A.D.S., Buseth, T., Krauter, S. and Grunow, P. (2010) Hot Spot Risk Analysis on Silicon Cell Modules. 25th European Photovoltaic Solar Energy Conference and Exhibition/5th World Conference on Photovoltaic Energy Conversion, Valencia, 6-10 September 2010, 4002-4006.

[24] Haeberlin, H. and Real, M. (2007) Arc Detector for Remote Detection of Dangerous Arcs on the DC Side of PV Plants. 22nd European Photovoltaic Solar Energy Conference, Milano, 3-7 September 2007.

[25] Yang, S., Bryant, A., Maybap, P., Xing, D. and Tanver, P. (2011) An Industry Based Survey of Reliability in Power Electronics Converters. IEEE Transactions on Industry Applications, 47, 1441-1451. http://dx.doi.org/10.1109/TIA.2011.2124436

[26] Callega, H., Chan, F. and Uribe, I. (2007) Reliability Oriented Assessment of a DC/DC Converter for Photovoltaic Applications. 2007 IEEE Power Electronics Specialists Conference, Orlando, 17-21 June 2007, 1522-1527. http://dx.doi.org/10.1109/PESC.2007.4342221

[27] Teoh, W.Y. and Tan, C.W. (2011) An Overview of Islanding Detection Methods in Photovoltaic Systems. World Academy of Science, Engineering and Technology, 5, 10-29.

[28] Seo, G.-S., Lee, K.-C. and Cho, B.-H. (2013) A New DC Anti-Islanding Technique of Electrolytic Capacitor-Less Photovoltaic Interface in DC Distribution Systems. IEEE Transactions on Power Electronics, 28, 1632-1641.

http://dx.doi.org/10.1109/TPEL.2012.2208226

\section{Submit or recommend next manuscript to SCIRP and we will provide best service for you:}

Accepting pre-submission inquiries through Email, Facebook, LinkedIn, Twitter, etc.

A wide selection of journals (inclusive of 9 subjects, more than 200 journals)

Providing 24-hour high-quality service

User-friendly online submission system

Fair and swift peer-review system

Efficient typesetting and proofreading procedure

Display of the result of downloads and visits, as well as the number of cited articles

Maximum dissemination of your research work

Submit your manuscript at: http://papersubmission.scirp.org/ 